\title{
El contenido burgués de las revoluciones de independencia en América Latina*
}

Manfred Kossok

Desde hace tiempo se percibe en la historiografía internacional, un notable avance de la investigación comparada, que en creciente medida repercute también sobre la historia de las revoluciones de los tiempos modernos. El método histórico comparado es un instrumento importante para aprehender la relación entre lo general y lo particular, entre las manifestaciones concretas que adoptan las leyes históricas y la "repetitividad" de procesos (congruentes tanto con el sistema como con el estadio histórico) propios a determinada formación socioeconómica.

Por lo que toca a las posibilidades y limitaciones del método E. E. Pechuro se refería a ellas basándose en la posición teórica del investigador, el nivel del instrumental historiográfico y el desarrollo general del pensamiento histórico. ${ }^{1}$ Sin duda la investigación comparada debe tomar en cuenta la necesidad de una relación cuidadosamente equilibrada entre coordenadas teórico-metodológicas y casos concretos sólidamente fundamentados. Por una parte, el método comparativo es imprescindible para una concepción verdaderamente universal de la historia, que no destaque "centralmente" ninguna región; por otra parte, este proceder ha de someterse de continuo a la prueba empírica proporcionada por el acontecimiento concreto. Sólo así se logra limitar la excesiva relativización de los fenómenos históricos que tiende a justificar la negación de la teoría y la concepción, según la cual la historia "general" es historia falseada. ${ }^{2}$ El resultado no sería otro que el regreso a la perspectiva individualizadora exagerada del historicismo idealista. ${ }^{3}$

En qué medida se encuentra el método comparativo aún en sus comienzos a pesar de la abundantísima literatura ${ }^{4}$ (sin exclusión de la historiografia marxista ${ }^{5}$ ) lo revelan ciertas incertidumbres que prevalecen en el campo de la historia comparada de las revoluciones. No son pocos los trabajos que exhiben este título y, que más bien se reducen a ensayos paralelos ("sintesis de encuadernador") sobre procesos que se perciben análogos, o bien pertenecen

* Historia y Sociedad. México, $2^{\mathrm{a}}$ época, núm. 4, invierno de 1974, p. 61-79.

E. E. Pechuro, "Sravnitel'no-istoricheski-metod", en: Sovietskaya Istoricheskava Enciklopediya (SIE), Moscú, 1971, t. 13, p. 755.

- A. Caso, citado en: Do the Americans have a Common History?, Nueva York, L. Hanke, 1966, p. 25.

${ }^{3}$ I. S. Kon, Die Geschichtsphilosophie des 20. Jahrhunderts, Berlín, 1964, t. 1, p. 30 y ss.

+ Véase Th. Schielder, "Moglichkeiten und Grenzen vergleichender Methoden in der Geschichtswissenschaft", en: Historische Zeitschrift, t. 200, 1965.

s Pechuro, op. cit., p. 758; M. Kossok, W. Markov, "Zur Methodologie der vergleichenden Revolutionsgeschichte der Neuezeit", en: Studien zur vergleichenden Revolutionsgeschichte 1510-1917, Berlín, M. Kossok, 1974, p. 1 y ss. 
de hecho al campo de la teoria y filosofia de la revolución y no al de la historia como tal. ${ }^{6}$ Aunque demos por sentado que en el análisis comparado y su exposición, los tres aspectos mencionados no están separados por murallas chinas, es tarea del historiador desarrollar primero lo que es especifico de la historia comparada de las revoluciones. Las posibilidades del examen histórico comparado dependen en gran medida del nivel alcanzado por la investigación de los acontecimientos que constituyen en cada caso base y objeto de la comparación. De ello resulta, no por azar, sino como reflejo del nivel real del conocimiento, que las revoluciones modernas y especialmente la revoluciones clásicas, es decir, las revoluciones burguesas de los siglos XVII, XVIII y XIX (sobre todo la de 1848-49) que por su desarrollo y estructura han marcado una época y se consideran típicas, ${ }^{7}$ están en el centro de la atención científica.

En última instancia, es incontrovertible el rasgo universal de los acontecimientos de $1789-1794 / 95,{ }^{8}$ pese a los intentos -como los de R. R. Palmer $-{ }^{9}$ de reducir "a su minima expresión" la significación cardinal de la gran Revolución francesa en el análisis comparativo de las revoluciones burguesas, de la etapa de transición del feudalismo al capitalismo. Con base en esto quedan planteadas las premisas esenciales para comprender revoluciones similares anteriores, contemporáneas y posteriores, a partir de una comparación entre ellas.

Tomando en cuenta que las revoluciones de $1640,^{10} 1789^{11} \mathrm{y}$ (con cierta reserva) la de $1848 / 49,,^{12}$ no han sido estudiadas hasta ahora exhaustivamente mediante el método comparativo, ¿qué podemos decir de las posibilidades de este enfoque respecto a otras revoluciones de alcance histórico menor que, por su localización geográfica, aparentemente desempeñan un papel periférico? Por lo que hace a la revolución de independencia de Latinoamérica su pertinencia es innegable, ya que la lucha de 1790-1824 se da en una época determinada por la nueva realidad histórica de al-

${ }^{6}$ El estudio de L. P. Edwards, The Natural History of Revolution, Chicago-Londres, 1970, sigue siendo valioso, con la excepción de los desafortunados pasajes en donde se comparan las revoluciones socialistas con las burguesas. De este estudio de pioneros, publicado por primera vez en 1927 , M. Janowitz dice con razón en la introducción (p. IX) que ha sido superado por el libro de C. Brulons, The Anatomy of Revolution publicado en 1938.

${ }_{7}$ A. N. Chistozonov, "Über die stadial-regionale Methode bei der vergleichenden historischen Erforschung der bürgerlichen Revolutionen des 16. bis 18. Jahrhunderts in Europa", en: Zeitschrift für Geschichtswissenschaft (ZfG), Berlín, año 21,1973 , cuaderno 1, p. 31 y ss.

Contra el trasfondo político de las tendencias a subestimar la Revolución francesa de 1789 , polemizó M. Reinhard en su articulo "Travaux et perspectives sur la Revolution francaise" en Annales, Economies, Societés, Civilisations, París, 1959, t. 14 , p. 553 y ss. Sobre el papel de esa revolución véase también A. Saboul, "La Revolution Francaise dans l'histoire du monde contemporain", en Studien über die Revolution, Berlín, M. Kossok, 1971, p. 62 y ss.

${ }^{9}$ R. R. Palmer, Das Zeitalter der demonkratischen Revolution. Eine vergleichende Geschichte Europas und Amerikas von 1760 bis zur franzosischen Revolution. Francfort/M., 1970 (primera edición en inglés, 1959).

${ }_{10}$ Angliiskaya Burzhuaznaya Revolyuciya XVII veka, Moscú, E. Kosminski y J. A. Levickii, 1954, 2 tomos.

11 W. Markov y A. Soboul, Die Grosse Revolution der Franzosen, Berlín, 1974.

12 Revolucii 1848-1849. Moscú, F. V. Potemkin y A. I. Molok, 1952, 2 tomos. 
cance mundial que definió la Gran Revolución de los franceses. ${ }^{13}$

En la abundantísima literatura sobre la historia de la revolución de independencia latinoamericana, ${ }^{14}$ la aplicación del método comparativo casi no ha tenido partidarios. El magno intento a cargo del Instituto Panamericano de Geografía e Historia de apadrinar una Historia General de América, basada en una comparación a nivel continental, no ha rendido hasta la fecha más que resultados parciales; ${ }^{15}$ tampoco dieron frutos las iniciativas de indoctrinación panamericana para una "Common History of the Americas". ${ }^{16}$ Hace poco J. Lynch presentó un notable esfuerzo por elevar el nivel de investigación internacional alcanzado en torno a las revoluciones de independencia hispano-americanas. ${ }^{17}$ Desde un punto de vista marxista, W. Z. Foster, ${ }^{18}$ intentó clasificar la emancipación latinoamericana dentro del ciclo de una revolución americana general, de tipo burgués anticolonial. Empero, este innovador intento, que rebasa la energia de un investigador aislado, no ha encontrado en la demás historiografía marxista la merecida continuación. $^{19}$

R. Konetzke decía, a propósito de lo complicado del desarrollo real de las revoluciones y del nivel de investigación actual: "La historia de los movimientos revolucionarios que promovieron el surgimiento de Estados independientes, está en un proceso de revisión crítica, de reconocimiento más amplio y más profundo y de una interpretación, en muchos aspectos, nueva." 20 Pero en vista de la amplia gama de variaciones en las condiciones sociales y geográficas, Konetzke ve pocas posibilidades para una "teoría general de las revoluciones latinoamericanas". ${ }^{\mathrm{P}} \mathrm{Su}$ escepticismo es comprensible si se considera que haciendo caso omiso de las aberraciones del culto a los héroes ${ }^{22}$ de corte liberal o conservador, la historiografía tradicional sobre las revoluciones de independencia generalmente se ha mantenido entre dos extremos: o la generalización programática sin una base empírica suficiente, o el asimilamiento en el detalle, con un desinterés absoluto por cuestionamientos trascendentes.

Preocupados por lograr una nueva interpretación, autores marxistas, en especial, pusieron en un primer plano el problema del

${ }^{13}$ W. Markov y A. Saboul, op. cit., p. 433 y ss.

14 Véase el Indice histórico español (Barcelona, 1953) bajo el rubro "América: Independencia" por la bibliografia incluida.

15 Para la revolución anticolonial de Norte, Centro y Sudamérica, véase Silvio Zavala, El periodo colonial en la historia del nuevo mundo, México, 1962, p. 291 y ss.

${ }^{16}$ Una introducción a la polémica sobre el tema, nos ofrece el trabajo citado en la nota 2.

${ }_{17}$ J. Lynch, The Spanish American Revolutions. 1808- 1826, Londres, 1973.

18 W. Z. Foster, Historia politica de las Américas, La Habana, Cuba.

19 Un precursor marxista, del estudio global del tema, es el trabajo colectivo Voijna zanezavisimost v. Latinskoy Amerike (1810-1826), Moscú, 1964. Compárese también M. S. Alperovich y L. Ju. Slgoskin, Novaya storiya stran Latinskoy Ameriki, Moscú, 1970 , p. 23 y ss.

?0 R. Konetzke, "Die Revolutionen und die Unabhängigkeitskriege in Lateinamerika", en: Historia Mundi, Berna, 1960, t. 9, p. 365 y ss.

il Ibid.

22 Véase el análisis crítico de G. Carrera Damas, El culto a Bolivar. Esbozo para un estudio de la historia de las ideas en Venezuela, Caracas, 1969. 
carácter potencialmente burgués de la revolución de independencia. $^{23}$

Esto se objetó, cuestionándose la existencia del elemento burgués por considerarse que la estructura social y económica dominante era feudal. ${ }^{24}$ Pero aquí se encuentra el primer y decisivo equivoco tanto en el sentido de una clara comprensión del concepto "burguesía" como en el de una clasificación histórica universal de la revolución de independencia.

La pregunta acerca del carácter y clasificación histórica de las revoluciones latinoamericanas de independencia, lleva al problema de la tipologia de la revolución. El punto de partida para la formulación de una respuesta, es la determinación de las fuerzas sociales motrices y hegemónicas del proceso revolucionario en una muy estrecha relación dialéctica con el carácter de la época, es decir, la determinación de las potencias económicas, sociales, político-institucionales y cultural-espirituales que determinan todo el movimiento histórico. En otras palabras: la localización histórica de una revolución no sólo se halla determinada por las condiciones internas (indudablemente dominantes) sino también, con diferente gradación, por las leyes y condiciones universales del movimiento histórico, que actúan acelerando o retardando, influyendo y orientando. Es obvio que un complejo tal de factores, que afecta directamente o en forma inmediata tanto al acontecimiento como a la personalidad individual, no puede captarse sólo bajo el rubro de "condiciones externas". La esencia de la dialéctica revolucionaria más bien consiste en que -independientemente del problema aislado de la "exportación" de la revolución o de la contrarrevolución- en determinados momentos las condiciones "internas" y "externas" quedan indisolublemente ligadas.

La suma de las revoluciones, que, dependiendo de los grados de madurez del capitalismo marcan a nivel nacional, regional o universal las correspondientes etapas de sustitución de la sociedad feudal por la burguesa, son rubricadas con la categoria fundamental de "revolución burguesa". ${ }^{25}$ De acuerdo con las condiciones históricas concretas, bajo las cuales se desenvolvieron las revoluciones en la época de transición del feudalismo al capitalismo plenamente desarrollado, es decir de finales del siglo XV a mediados del XIX, se requiere de otra diferencia tipológica de la categoría básica "revolución burguesa". Con la definición muy usada de "revolución anticolonial" para caracterizar la transformación iniciada por el levantamiento de Haití en 1790 y de Iberoamérica a partir de 1810 , se logró aprehender un elemento básico de su contenido y meta, pero no se arrojó luz sobre las fuerzas sociales motrices y, por consiguiente, sobre el carácter de clase del movimiento de independencia, tanto menos cuanto precisamente el frente antifrancés, antiespañol o antiportugués estaba muy dis-

${ }^{23}$ Foster, op. cit.; M. Kossok, Historia de la Santa Alianza y la emancipación de América Latina, Buenos Aires, 1968, p. 13 y ss: Aportaciones de N. M. Lavrov, V. I. Ermolaev, F. A. Granin, en el libro citado en la nota 19.

${ }_{24}$ Konetzke, op. cit., p. 367. Subrayado por R. H. Humphreys y J. Lynch, "The Historiography of Spanish-Americas Revolution", en: Relationi (Com. Int. di Scienzo Storichi), Roma, 1955, t. I, p. 78.

${ }_{23}$ Véase el articulo "Burzhuaznaya revolyuciya", en: SIE, t. 2, p. 842 y ss. 
puesto a aglutinar en una oposición común a clases y estratos divergentes y aun antagonistas, por lo menos temporalmente.

Podria procederse a una clasificación comparada de los movimientos de independencia latinoamericanos dentro del ciclo revolucionario que se inaugura con el viraje de 1789 (con respecto al cual la guerra de independencia norteamericana cumplió sin duda una función precursora), tomando como punto de partida el concepto ciclo revolucionario en su sentido amplio y en su sentido estricto. ${ }^{26}$

1. Ciclo revolucionario en sentido amplio quiere decir preguntar según la importancia histórica:

a) a nivel universal,

b) a nivel continental:

¿Qué papel jugó a escala mundial la revolución latinoamericana de independencia en la época del triunfo definitivo del orden capitalista burgués, iniciada por la Revolución francesa de 1789-1794/ 95? ¿Qué función histórica tuvo el movimiento de independencia como eslabón de una cadena de movimientos de emancipación anticolonial, que en distintas etapas se habian producido en el continente americano desde 1775 ?

2. La problemática del ciclo revolucionario en sentido estricto se refiere a:

a) el carácter cíclico de la revolución de independencia como tal y

b) su conexión interna con la revolución en las respectivas metrópolis (Haití-Francia; Iberoamérica-España-Portugal). ${ }^{27}$

Independientemente de los diversos niveles de relación, surge como criterio determinante de interpretación histórica comparada, la cuestión del grado de afinidad, entre un país y otro, de las fuerzas de clase, instituciones e ideologias portadoras de la transformación revolucionaria.

Mientras en el caso de Haití se perfiló un claro desarrollo lineal ascendente, que alcanzó su culminación burguesa-democrática en la dictadura del jacobinismo negro bajo Toussaint L'Ouverture, ${ }^{28}$ las cosas son mucho más complicadas por lo que respecta a la América española y portuguesa.

A fin de abarcar cronológicamente los sucesos revolucionarios en el ámbito colonial ibérico se puede recurrir a la siguiente periodización:

1) 1789-1808: Crisis de la dominación colonial. Van madurando las condiciones objetivas y subjetivas para el surgimiento de una oposición anticolonial (tomando en consideración el efecto definitivamente discrepante que sobre las clases altas criollas tuvieron el radicalismo jacobino y la emancipación esclavista en Haití).

26 Véase M. Kossok, J. Kübler y M. Zeuske, "Ein Versuch zur Dialektik von Revolution und Reform in der historischen Entwicklung Lateinamerikas (1809. 1917)", en: Studien zur vergleichenden Revolutionsgeschichte, op. cit.

${ }^{27}$ M. Kossok, "Der iberische Revolutionszyklus 1789-1830. Betrachtungen zu einem Thema der vergleichender Revolutionsgeschichte", Berlín, M. Kossok, 1971 , p. 208 y ss.

${ }_{28}$ Véase T. Lepowski, Haiti, Habana, 1968 (Estudios del Centro de Documentación Juan F. Noyola), t. 1 , p. 62 y ss., t. 2 , p. 11 y ss. 
2) 1808-1809: Surgimiento de una situación revolucionaria (bajo la influencia decisiva pero no linealmente causal de los sucesos ocurridos en la península ibérica desde 1807).

3) 1810-1815: Primera fase de la revolución de independencia (después de una escalada continental, sigue una derrota casi continental con excepción del centro revolucionario de Buenos Aires).

4) 1815-1824: Segunda fase de la revolución de independencia (con el viraje decisivo de Ayacucho y la separación de Brasil).

Sin embargo, este esquema del curso general de los acontecimientos, no es suficiente para revelar la complejidad de los hechos reales del proceso revolucionario. La objeción formulada por Konetzke en contra de una "teoria general" merece nuevamente consideración a la luz de la siguiente observación:

Las investigaciones recientes, fuertemente orientadas hacia lo económico y lo histórico-social, han conducido a importantes descubrimientos acerca de las causas, el carácter y el curso de la revolución de independencia. Los trabajos de historia política, institucional, ideológica y diplomática, no pierden con ello valor, pero en creciente medida son colocados en una relación correcta con la totalidad de los factores en acción y la totalidad de los acontecimientos. El problema metodológico consiste en cómo y en qué medida es posible definir la dialéctica -característica de Latinoamérica- entre unidad y multiplicidad del desarrollo histórico, ${ }^{29}$ en la exposición de la revolución de independencia. No es ocioso meditar acerca de la necesidad de hablar de revolución o revoluciones. La primacia del carácter continental de la revolución de independencia en la América hispánica, especialmente durante la primera etapa, no puede cuestionarse. Sin embargo, el peso creciente que fueron adquiriendo los Estados nacionales, es decir, el factor de la paulatina división de la revolución en componentes independientes en sentido político y territorial, no es expresión de un fracaso de la emancipación, sino más bien, de la tendencia ineludible a la formación de Estados nacionales potencialmente burgueses. ${ }^{30}$ Fenómeno que corresponde al carácter de la época y no deja de ser, por lo demás, un criterio importante para comprender la sustancia fundamentalmente burguesa del movimiento de emancipación.

El historiador se encuentra todavía frente a dos dificultades primordiales en la caracterización de las fuerzas motrices de la emancipación. Estas resultan, por una parte, de la marcada congruencia que existe entre la diferenciación social y la étnica -resultante de la situación colonial específica- y por otra, de las diferencias geográficas y económicas, que se dan entre región y región.

La relativa identidad entre el status étnico y el social ${ }^{31}$ dio con

\footnotetext{
${ }^{29}$ M. Kossok, "Common Aspects and Distinctive Features in Colonial Latin America", en Science and Society, Nueva York, t. 37, núm. 1, 1973, p. 1 y ss.

${ }^{30}$ Kossok, "Zur Spezific von Nationwerdung und Staatsbildung in Lateinamerika", en Zeitschrift für Geschichte, 1970, cuaderno 6, p. 750 y ss. Cuando algunos historiadores, después de observar la dimensión casi continental de los E.U. consideran como posible el surgimiento de una nación única a raiz de la revolución de 1810, se olvidan de un hecho cardinal: que la expansión posterior de los E.U. es el resultado no de una revolución, sino de un proceso de colonización.

${ }^{31}$ Véase la investigación de M. Mörner sobre ese problema, Race Mixture in the History of Latin America, Boston, 1967.
} 
frecuencia enfrentamientos, que en última instancia se originaban en conflictos de clase, el aspecto de un conflicto racial o -para emplear la terminología contemporánea- de una "guerra de castas". Tal deformación o desplazamiento de los frentes de combate reales, no fue en modo alguno de poca significación, ya que determinadas normas legales se atenian a la procedencia étnica y no al status social. ${ }^{32}$ Con frecuencia el elemento étnico se sobreponia a la conciencia social: entonces, la protesta social adquiria la forma de un racismo introvertido mientras que para las clases dominantes la emancipación de las masas populares liberaba al espectro de la "pardocracia". Resulta apenas necesario dar ejemplos detallados para explicar el grado en que esto dificultaba la alianza de diversas clases y capas en su lucha por las metas "nacionales" comunes. Cuando Toussaint L'Ouverture, en Haití, o Hidalgo en México trataron de ganar para la causa de la revolución a algunos estratos criollos, ${ }^{33}$ no recibieron un apoyo indiviso por parte de los voceros más radicales del movimiento popular, que ante todo eran "antieuropeos" o "anticriollistas".

Pese al consenso creciente entre los historiadores, de que la predominante diferenciación étnico-jurídica institucionalizada de la Colonia debe investigarse a partir de la estructura de clases real, económica y socialmente determinada, se mantiene empecinadamente la tradición de dividir la sociedad en españoles (portugueses) europeos, criollos, mestizos, indios, mulatos, negros. Los conocimientos obtenidos con respecto a la estructura económica de la última etapa colonial no han encontrado expresión suficiente en un análisis detallado de las relaciones de clase. Estas lagunas en la investigación son tanto menos sorprendentes si se considera que aun en la investigación de la Revolución francesa de 1789 , falta una historia de la burguesia o del campesinado, comparable a la innovadora obra que A. Soboul ${ }^{34}$ escribió sobre la sansculotterie urbana.

El esquema siguiente aclara, simplificando mucho, la relación multilineal que existe entre la estructura de clases y la diferenciación étnica en la América hispana en vísperas de la revolución de independencia (véase el esquema).

Se hace asi necesaria la investigación en dos direcciones:

1. Cómo se configuró la relación cuantitativa y cualitativa entre las diferentes categorías.

2. Qué diferenciaciones regionales y locales importantes se dieron dentro de la estructura "general" de lo social y lo étnico.

El segundo punto tuvo una gran influencia sobre la exposición histórica concreta, es decir, en este caso, específica regional, del desarrollo de la revolución. Bastará a este respecto llamar la atención sobre un problema especialmente importante: la cuestión agraria.

La preocupación social fundamental de toda revolución bur-

32 El argumento decisivo que demuestra el dominio en última instancia de las categorias de clase social, es la posibilidad bien conocida de comprar la "limpieza de sangre". El dinero era el mejor blanqueador.

${ }^{33}$ Para Toussaint L'Ouverture véase Lepkowski, op. cit:

${ }^{34}$ A. Soboul, Les sans-culottes parisien en l'an II. Mouvement populaire et gouvernement revolutionnaire. 2 jun. $1793-9$ thermidor an II, La Roche-sur-Yon, 1958. 
Burocracia colonial (incluyendo alto clero y comerciantes de ultramar)

\section{Latifundistas} (incluyendo dueños de minas y obrajes

\section{Comerciantes}

Oficios libres (incluyendo bajo clero)

\section{Artesanos (privilegiados)}

Artesanos (no privilegiados)

\section{Campesinos} (libres)

\section{Campesinos}

(en dependencia feudal)

\section{Proletariado}

(diversas categorias)

\section{Esclavos}

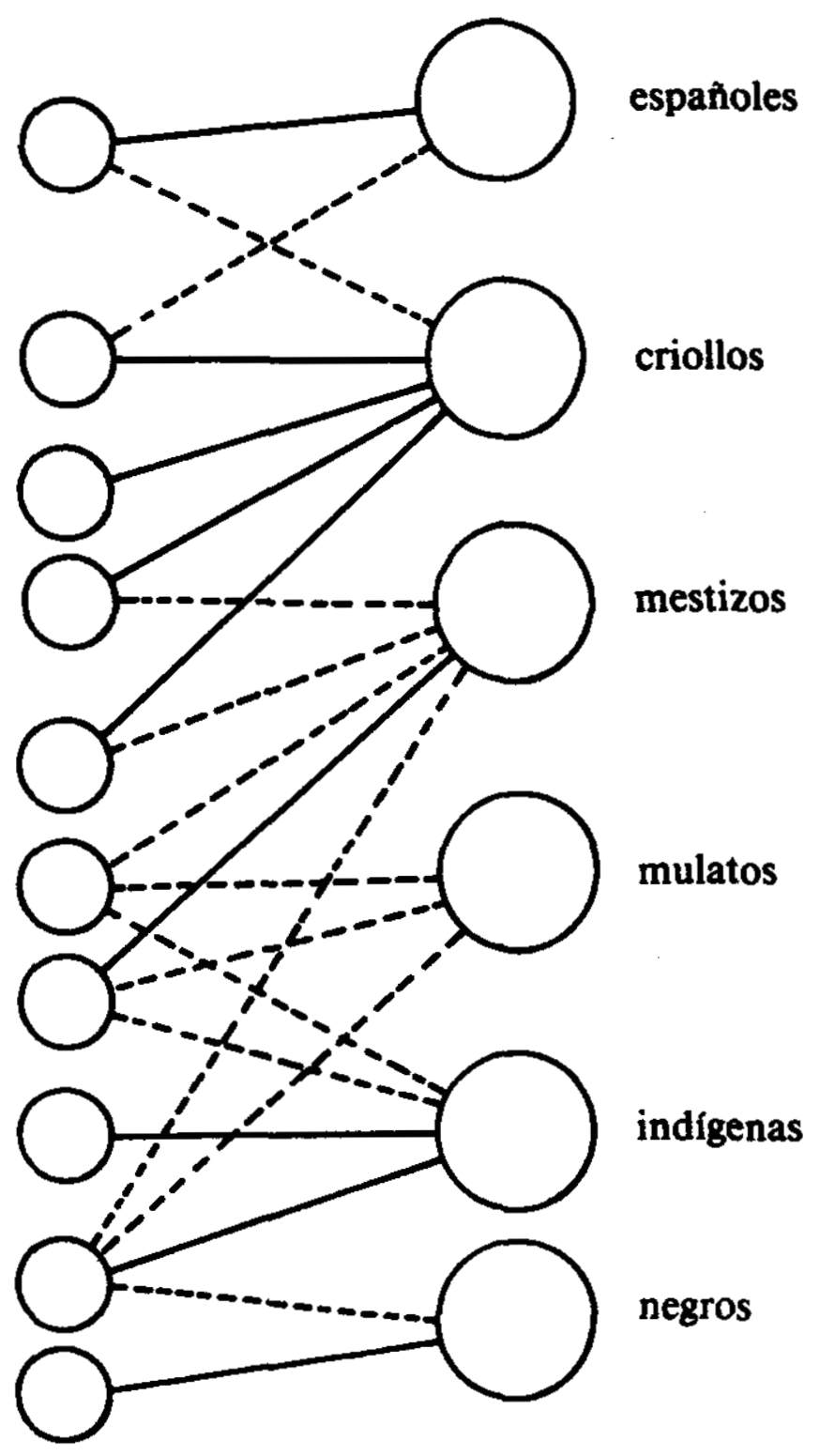

\section{Relación predominante}

... Relación secundaria 
guesa -la eliminación de las formas precapitalistas de producción, explotación y dependencia- ${ }^{35}$ fue también de importancia decisiva para la revolución de independencia latinoamericana. De acuerdo con la pluralidad de las formas de producción existentes, ${ }^{36}$ la superación de las relaciones de producción y de propiedad precapitalistas no se redujo a la liquidación de las formas feudales; también estaban presentes la propiedad comunal indigena campesina (uno de los bastiones más potentes contra el desarrollo de un mercado interno y la "capitalización" de la estructura agraria) y la esclavitud en las plantaciones, esta última, como "anomalia" 37 dentro de una producción capitalista de alcance mundial. De la diferencia en las relaciones de producción resultó una muy diferente estructura agraria que se acentuaba con la diferenciación regional: en los "confines limítrofes" de la América hispánica ${ }^{38}$ (como por ejemplo la región del Plata, el norte de México y las planicies del Orinoco en Venezuela), donde dominaba la cría de ganado, la formación de los grandes latifundios ocurría con retraso y en formas muy específicas; la situación era muy diferente en las zonas intensamente pobladas del centro de México o del altiplano peruano-boliviano.

Las especulaciones abstractas sobre la estructura y función del latifundio, por ejemplo de las haciendas, ${ }^{39}$ fallan necesariamente ante la multiplicidad de los fenómenos concretos. El "fracaso", frecuentemente mentado, de la cuestión agraria como criterio para afirmar la no-consumación de la revolución de 1790-1824 tiene un carácter extremadamente contradictorio: la eliminación de estructuras parciales precapitalistas en un sector, podia conducir a la consolidación de estructuras precapitalistas en otro sector. Tanto la supresión del sistema tributario como de la esclavitud (aunque retardada) -quedando comprendidas ambas unívocamente en el más amplio contexto de transformación burguesa- no condujeron, dada la relación de fuerzas de clase, a una irrupción consecuente del desarrollo capitalista agrario, sino que bajo la dirección de la aristocracia terrateniente criolla, llevaron a una estabilización de formas de dependencia feudales y semifeudales.

${ }^{35}$ Véase B. P. Kuznetsov, G. G. Kosminskii, E. A. Luckii, "Agrarny vopros”, en SIE, t. 1 , p. 173 y ss.

${ }^{36}$ M. Kossok, "Feudalismo y capitalismo en la historia colonial de la América Latina", en Comunidad, México, núm. 46, 1973, p. 642 y ss.

37 Véase las observaciones de Laclau basadas en Marx en "Feudalismo y capitalismo en América Latina", A. G. Frank, R. Puiggros, E. Laclau, América latina, ¿feudalismo o capitalismo?, Bogotá, 1972, p. 136 y ss.

${ }^{38}$.Sobre el problema de la "Frontera" en América colonial, véase M. Kossok, "Estructura y función de la frontera en la América española", en Wissenschaftliche Zeitschrift der Karl Marx Universitat, Gesellschaft und sprachwissenschaftliche Reihe, año 19, cuaderno 3,1970, p. 4-19 y ss.

${ }_{39}$ Nuevas perspectivas fueron abiertas por el Simposium 6 (Historia Económica de América Latina) del XL Congreso Internacional de Americanistas.

40 "Miesa redonda sobre el libro Historia del capitalismo en México. Los origenes de Enrique Semo", en Investigación Económica, México, vol. 32, núm. 128, oct.dic., 1973, p. 819 y ss. (Aportación de Enrique Semo, p. 846 y ss.); A. Quimbaya, Cuestiones colombianas. Ensayo de interpretación y crítica, Bogotá, 1958, p. 209 y ss.; P. I. Muñoz, "Breves anotaciones acerca de la esclavitud y de la liberación de los esclavos en Venezuela", en Boletín de la Academia Nacional de la Historia, Caracas, vol. 57 , núm. 225 , enero-marzo, 1974, p. 49 y ss. Sobre el ejemplo de España, J. M. Jover Zamora usó el concepto de "reforma agraria al revés" (A. Ubieto, J. Reglá, J. M. Jover, C. Seco, Introducción a la Historia de España, Barcelona, 1971, p. 556). 
La dimensión histórica de una revolución burguesa, depende de la madurez y concordancia de sus principales componentes de clase. En Francia, donde consideramos que se dio la revolución clásica del periodo de transición entre el feudalismo y el capitalismo, los componentes son:

el liberal burgués (con inclusión de ciertos sectores de la nobleza),

el pequeño burgués-democrático (sostén social del jacobinismo),

el campesino (que es a la vez la base de masas, de la revolución), y

el urbano-plebeyo (poco más tarde proletario).

A primera vista se puede reconocer que esta división no puede aplicarse sin más a las condiciones latinoamericanas de finales del siglo XVIII y principios del XIX. El papel de la Revolución francesa de 1789-1794/95, como revolución burguesa clásica, no implica la posibilidad de hablar de una revolución "modelo", con cuya vara se puedan medir todas las demás, destacando sólo las "divergencias". "deformaciones" e "irregularidades". Partiendo de ahí. haremos a continuación unas observaciones para esbozar las particularidades de la situación latinoamericana en el momento de iniciarse la revolución de independencia.

1. En comparación con la Inglaterra de 1640 (con una "revolución agraria" acabada) y con la Francia de 1789 (con claros indicios de una penetración capitalista del sector agrario) o también en comparación con los Estados Unidos (con un punto de partida casi burgués), ${ }^{42}$ Latinoamérica exhibía una estructura feudal-colonial en extremo rígida, que sólo limitadamente permitía un desenvolvimiento independiente del elemento productivo capitalistaburgués. ${ }^{43}$

2. Las crisis cíclicas del mercado internacional desde el último cuarto del siglo XVIII, junto con los efectos de la política borbona de liberalización condujeron a una decadencia de los centros de producción artesanal, mayor o menor según las regiones (Nueva España, Nueva Granada, Zona Interior del Virreinato del Río de la Plata), con el consecuente debilitamiento del elemento clasista burgués antifeudal.

3. La función híbrida de los grupos de latifundistas orientados hacia la exportación (dependencia del mercado mundial capitalista y simultáneamente conservación de formas de producción precapitalistas) confrontaba a la burguesía, aún embrionaria, con una clase que competía con ella y era la dominante, tanto económica como política y socialmente, y que bajo las condiciones de dependencia colonial obtenía apoyo del capitalismo desde afuera,

\footnotetext{
${ }^{41}$ A. Soboul, "Im Lichte von 1789. Theoretische Probleme der bürgerlichen Revolution", en Studien zur vergleichenden Revolutionsgeschichte, op. cit., p. 199 y ss.

${ }^{42}$ A. V. Jefimov, SSA, Puti razvitiya kapitalizma (Do imperialisticheskaya epocha), Moscú, 1969, p. 11 y ss.

${ }^{43}$ Sobre México véase E. Semo, Historia del capitalismo en México. Los orígenes 1521-1763, México, 1973, p. 230 y ss. Para la región del Plata véase M. Kossok, El virreinato del Río de la Plata, Buenos Aires, 1972.
} 
sin que "al interior" se volviese portadora de la transformación capitalista burguesa autóctona. Este fenómeno de utilización parcial de instrumentos capitalistas por parte de las fuerzas de clase precapitalista, especialmente feudales, se limita no sólo a Latinoamérica. Basta recordar el papel de la Mesta castellana ${ }^{44}$ o la penetración evolutiva del capitalismo en Europa oriental y del sur. ${ }^{45}$

Pero a pesar de su situación especificamente colonial, Latinoamérica no constituyó ningún caso aislado; por el contrario, adopta los dos caminos principales de la puesta en marcha del modo de producción capitalista (el camino "revolucionario" y el "conservador"), a los que corresponden tipológicamente, la revolución "desde abajo" y la revolución "desde arriba".46

4. En el elemento burgués naciente dominaba claramente la burguesía comercial (no tomando en consideración las capas intelectuales heterogéneas). Su fuerza no es, sin embargo, un criterio para medir la presencia de una burguesía antifeudal. Por el contrario, también para Latinoamérica se ve confirmada la capacidad del capital comercial, de aprovechar y conservar formas de producción y explotación precapitalista con el fín de la acumulación. ${ }^{47}$ En forma parecida a estas experiencias europeas, la burguesía comercial procuró su incorporación social y política a la aristocracia terrateniente, tomando los rasgos de "burguesía feudal" (A. Soboul) en el mejor de los casos reformista, pero por principio siempre contrarrevolucionaria.

5. Entre las condiciones señaladas, la burguesía (con un desarrollo estructural y regional extremadamente diverso: compárense Buenos Aires-Lima-México) no estaba capacitada para adoptar un papel hegemónico, es decir, para dirigir y dar a la revolución un sello propio. Permaneció así, una clara sumisión si no teórico-política (ideologia revolucionaria) sí práctico-política (resultados revolucionarios) a la influencia dominante de la fracción liberal anticolonial de los terratenientes criollos. Sin embargo, no debe concluirse de aquí que el componente burgués no haya existido o que haya sido tan insignificante que la pregunta acerca del carácter potencialmente burgués de la revolución de independencia resulta irreal; a tal proceder se oponen (aparte de las condiciones históricas universales de la época) por lo menos tres aspectos:

a) La debilidad real y el papel eminentemente local (en ningún caso ya nacional; ni siquiera en la región del Plata) de los elementos de clase burgueses, que no deben nunca confundirse con una no existencia.

b) La adopción de modelos ideales, congruentes con la época y por lo tanto fundamentalmente burgueses, por buena parte de la aristocracia terrateniente criolla (llustración, Constitución, libre comercio, etc.). ${ }^{48}$

\footnotetext{
${ }^{44}$ J. Klein, The Mesta. A Study in Spanish Economic History 1273-1836, Harvard, 1920.

45 Sobre este punto hay que tomar en cuenta las consecuencias de la "segunda servidumbre" y el "camino prusiano" del desarrollo.

${ }^{46}$ Soboul, "Im Lichte von 1789", op. cit.

${ }^{47}$ C. Marx, El capital, México, FCE, 1972, vol. 3, capítulo XXXVI.

${ }^{48} \mathrm{~L}$. Levene, El mundo de las ideas y la revolución hispanoamericana, Santiago de Chile, 1956.
} 
c) El papel del movimiento popular autónomo, que propugnando la emancipación anticolonial irrumpió en el campo del radicalismo democrático-burgués, ${ }^{49}$ en diversos focos del proceso revolucionario (por ejemplo en Haití bajo Toussaint L'Ouverture, en México bajo Hidalgo y Morelos, en Uruguay bajo Artigas, en Buenos Aires, en torno a Moreno-Monteagudo) lo que no dejó de tener resonancia en la conducta de las fuerzas moderadas.

A consecuencia de no haberse dado una hegemonía "pura" de carácter burgués, o aun pequeñoburgués, sobre todo en el proceso o en periodos prolongados de la revolución; como consecuencia también de la importancia de fuerzas a quienes interesaba primariamente la emancipación política nacional, y no la emancipación social, faltó la base de clase decisiva para movilizar en toda su amplitud el movimiento popular e integrarlo permanentemente a los planteamientos históricos de la revolución anticolonial.

Análogamente, en la medida en que sectores criollos-aristocráticos del partido revolucionario entendian la independencia como segundo frente de lucha ("hacia arriba", es decir "hacia afuera" contra España y Portugal, "hacia abajo" contra el radicalismo de las "castas"), la relación de las clases populares con la revolución tenía que ser una relación quebrantada y ambivalente. Si por momentos la contrarrevolución realista lograba alcanzar una auténtica base de masas y ser el primer partido que ponía a la orden del dia la "guerra a muerte", el desarrollo que se daba nada tenía que ver con "inmadurez" o "desorientación" de las clases populares, sino que surgía más bien de la división social interna en el campo de la lucha anticolonial. La primacia concedida al "frente exterior" no fue lo suficientemente eficaz, como para impedir -sobre todo hacia la fase final de la revolución (aproximadamente a partir de 1821-1822)- un viraje conservador. Queda como tarea aclarar en forma diferenciada el papel de los componentes políticos y sociales más importantes: ¿dónde, por cuánto tiempo y con qué intensidad corren paralelos, fortificándose uno al otro?, ¿dónde adopta su desarrollo un curso contrario hasta llegar a ser abiertamente antagónico?

Partiendo de las relaciones dialécticas entre las clases y capas que intervinieron, del contenido social del movimiento y de la especificidad de las fuerzas hegemónicas, parece posible dividir tipológicamente el ciclo total continental de la revolución de independencia latinoamericana de 1790-1824, en cuatro corrientes, por lo menos.

1. La corriente revolucionaria democrática, caracterizada por la intervención independiente y determinante de las masas populares, con una radicalismo social y político que sería el más congruente en la lucha contra el sistema colonial.

2. La corriente criolla-republicana, cuya intransigencia política excluyó el compromiso político con la potencia colonial y sus pilares institucionales; esta corriente fue la dominante durante la re-

${ }^{44}$ Sobre la relación entre revolución burguesa y revolución democrático-burguesa, véase W. Kütler, "Zum Begriff der bürgerlichen und bürgerlichdemokratischen Revolution bei Lenin", en Studien zur vergleichenden Revolutionsgeschichte, op. cit. 
volución y alcanzó una base de masas bastante considerable.

3. La corriente liberal-criolla que representaba fundamentalmente un reformismo moderno y -sin renunciar a la independencia como meta política- perseguía un compromiso con la potencia colonial; en parte debido a un auténtico entrelazamiento de intereses (Villoro acuñó el significativo concepto "clase eurocriolla"), en parte por su creciente distanciamiento de los amenazantes conatos de una revolución "desde abajo".

4. La corriente conservadora como expresión del rechazo militante al levantamiento de las clases populares, rechazo nacido del designio hegemónico criollo-aristocrático, o también resultado de una oposición diametral al levantamiento de las clases populares, o una oposición al peligro de que la revolución liberal burguesa se gestara desde la metrópoli; es decir, propugnaban una independencia para defender el statu quo.

Mientras que la corriente revolucionaria democrática permanece claramente separada de todas las otras corrientes en todo momento, entre las corrientes nombradas bajo los números 2 hasta 4 , se dieron zonas de transición relativamente amplias. De ellas, por otra parte, las más definidas se sitúan entre la 3 y la 4 .

Carlos Marx, partiendo de la comparación entre las revoluciones francesas de 1789 y 1848, se pregunta si la línea de desarrollo de la revolución es ascendente o descendente, ${ }^{51}$ entendiendo por línea ascendente la sucesión progresiva, por etapas, de las fracciones dirigentes, y la radicalización ligada a ella, así como finalmente la culminación de la revolución. Esta pregunta requiere con respecto a Latinoamérica (con la ya indicada excepción de Haití) de un debate que la aclare más; consumación de la revolución no quiere decir de ninguna manera que en todos los casos, como dijo Lenin, se elimine directamente la base de la que surge la revolución burguesa. También la Francia "clásica" necesitó de una secuencia de tres revoluciones hasta lograr la cabal creación del orden capitalista burgués; para muchos otros paises (como por ejemplo Inglaterra, Estados Unidos, Alemania, Italia, España, Portugal, Rusia) fueron necesarias varias revoluciones, o periodos de reformas en los que se gestaba la revolución, para eliminar la "base" del antiguo orden. La consumación de cada una de las revoluciones, quiere decir, por lo tanto, agotar consecuentemente las posibilidades existentes en el momento histórico dado. Precisamente esta realización de las posibilidades objetivas presupone el cambio progresivo en la hegemonia; dicho metafóricamente, la jacobinización tendencial de una revolución.

Los cambios en la hegemonía, ligados al trazo progresivo-ascendente o regresivo-descendente de la curva de la revolución, como expresión de un cambio positivo o negativo en la constelación de las fuerzas de clase, constituye al mismo tiempo un criterio para la periodización de una revolución. La cesura de los años 18151816 en Latinoamérica reconocida como giro entre la primera y segunda fase de la revolución, corresponde por de pronto al curso

${ }^{50}$ L. Villoro, La revolución de independencia, México, 1953.

si C. Marx, "El 18 Brumario de Luis Bonaparte", Obras escogidas, Moscú, Ed. Progreso, 1969. 
exterior político militar de los acontecimientos y del desarrollo de las premisas internacionales. Sin embargo, sabemos muy poco aún sobre los cambios ocurridos dentro del campo revolucionario mismo. ¿A qué conclusiones llegaron las fuerzas directrices con respecto a la catastrófica derrota de la primera fase?, ¿cómo se estructuró, a partir de entonces, la relación entre la dirección de la revolución y la base de masas?

Las experiencias de la primera fase de la revolución demostraron con suficiencia que a raíz del antagonismo de intereses latentes entre las clases populares y la aristocracia terrateniente y la burguesia comercial criolla, la contrarrevolución realista española encontró siempre punto de apoyo para una restauración del antiguo orden:

a) Uno de los problemas sociales fundamentales de la emancipación -ya citados-, la liberación de los esclavos, no se abordó o se hizo sólo bajo condiciones discriminatorias. Los proyectos de la ley abolicionista llevaban evidentemente la marca de una alianza, "para no lastimar los intereses de los propietarios". 52 El temor de que de la emancipación de esclavos naciera un Haiti continental, paralizó a la mayoría de la oposición criolla. La famosa "Carta de Jamaica" de Simón Bolívar es un documento clave para esclarecer el cambio positivo ocurrido en las posiciones desde 1815-1816. Para Brasil, la coyuntura de la esclavitud en las plantaciones se encontró apenas en la fase posterior a la emancipación. ${ }^{53}$

b) También la situación social del campesinado indigena dependiente permaneció intacta con los primeros pasos de la revolución. Los terratenientes, independientemente de que tuvieran una orientación radical republicana o moderada liberal, estuvieron interesados primariamente en la eliminación de aquellas formas de dependencia que ataban a los "co" ciudadanos indígenas a la Colonia española. Pero el levantamiento de los terratenientes no significó de ninguna manera la emancipación del campesino sino la cabal consolidación del dominio criollo aristocrático. Una expresión y resultado trágico de estos intereses sociales en contradicción, fue la derrota de la revolución dirigida por Hidalgo y Morelos en México. ${ }^{54}$ Utilizando el instinto de propiedad de lós grandes terratenientes criollos, el virrey español logró una alianza justamente con esos círculos que en 1821 consumarian la independencia (por ejemplo Iturbide), aunque por supuesto con la certidumbre de mantener incólumes los deslindes sociales procedentes de los tiempos de la Colonia, que afectaban a las clases populares. En la conservación de la jerarquía social, se hallaba la condición necesaria para la consumación de la independencia. No podia expresarse en forma más clara el desarrollo contrario de los componentes de la revolución.

El efecto tan intenso que tendría la dialéctica real del desarrollo de la revolución sobre la conducta táctica de determinados grupos, se ve muy claro en estos dos sucesos.

52 Lo que sostiene L. Galdames (Historia de Chile, Santiago de Chile, 1945, p. 256) sobre Chile, es válido para toda América Latina.

${ }^{33}$ C. Prado Junior, Historia económica del Brasil, Buenos Aires, 1960, p. 195 y ss.

${ }^{54}$ M. S. Alperovich, "Hidalgo und der Volksaufstand in Mexiko", en Lateinamerika zwischen Emanzipation und Imperialismus, Berlin, 1961, p. 35 y ss. 
Bajo la influencia de los intentos de legislación antifeudal de Hidalgo y Morelos las autoridades coloniales se vieron compelidas a promover decretos análogos, cuyo texto (a diferencia de la versión en español del de los insurgentes) se publicó en náhuatl y llegó a la mayoría de los indígenas mucho más rápida y efectivamente. ${ }^{55}$ Iturbide, por su parte, se vio obligado a absorber ciertas fracciones de la guerrilla ${ }^{56}$ para dotar a su propio movimiento de alguna base de masas.

Las circunstancias internas y externas menos favorables bajo las cuales hubieron de actuar Hidalgo y Morelos, condujeron a un complejo de problemas que hasta ahora no ha sido interpretado satisfactoriamente; de la historia de la grande peur y los posteriores oleajes revolucionarios espontáneos del movimiento campesino en la Revolución francesa de 1789 , se puede desprender que el movimiento agrario, inicialmente antifeudal, destructor, sería el vehículo decisivo para una transformación progresiva burguesa, en la medida en que lo acogería el sector hegemónico de la revolución, el pequeñoburgués-democrático de los jacobinos. ${ }^{57}$ Para México y el resto de Iberoamérica no existía sin embargo una coyuntura hegemónica y de clases análoga. Este ejemplo, empero, se presta para indicar el margen de variación en la dialéctica de una estructura agraria específica, el grado variable de madurez del potencial de clase burgués y el tipo de revolución que se derivara de lo anterior. ${ }^{58}$

Con excepción de la revolución esclavista de Haití, que tipológicamente tiene características muy particulares, la revolución de independencia latinoamericana, sólo en una región logró que el componente democrático revolucionario actuara en forma sostenida: en Paraguay bajo Rodriguez Francia. ${ }^{59}$ Sin embargo, debido a su extremo aislamiento la dictadura revolucionaria de Francia, no pudo ni irradiar su influencia sobre el resto de Sudamérica (la reacción de Bolívar, en el infeliz episodio Bonpland, revela más bien lo contrario) ni tampoco desembocó en la "normalización" interna de un periodo termidor.

Queda como un hecho que aquellos movimientos populares que (según el punto de vista del partido criollo), como alguna vez dijo Engels. llevaron a la revolución a rebasar sus objetivos, fracasaron; bien por la intervención (Haiti, Uruguay), por la supremacia militar de la contrarrevolución interna (México) o bajo el peso de un aislamiento forzoso (Paraguay). Existía ciertamente la posibilidad histórica de transformar mediante el empuje revolucionario social de las masas, el movimiento de independencia en una revolu-

${ }^{55}$ M. Kossok, Hidalgo und Morelos: Zur universalen Dimension des "prêtre rouge" (estudio en preparación).

${ }_{50}$ Ocherki novoi i novieshei istorii Meksiki, Moscú, 1960, p. 102 y ss.

${ }^{57}$ Soboul, "Im Lichte von 1789", op. cit.

${ }^{58}$ Una primera aproximación a la complejidad del problema presenta el trabajo de P. Vilar, Movimientos campesinos en América Latina, Moscú, 1970 (Comisión internacional de historia de los movimientos sociales y las estructuras sociales: Investigación sobre los movimientos campesinos en el mundo contemporáneo, $\mathbf{p}$. 76 y ss).

${ }_{54}$ Sobre la apreciación ilimitada favorable de Alperovich- Sloyozkin (op. cit.), se han formulado diversas críticas. 
ción de tipo democrático-burgués, pero fue finalmente bloqueada por la dirección moderada criolla-aristocrática de la revolución. Este desarrollo, que fue una de las causas fundamentales de la no consumación (social) de la revolución, significó naturalmente que se dejasen sentadas las bases negativas para el periodo posterior a la emancipación. Empero, es necesario señalar nuestras objeciones a dos juicios estandarizados de la historiografia liberal. La no-consumación social (y económica) no significó de ningún modo, que no hubiera transformación alguna tanto en lo social como en lo económico, la revolución "política" y la revolución "social" nunca existen en forma "pura" ni aislada una de la otra; también la revolución latinoamericana tuvo consecuencias socioeconómicas inmediatas o mediatas (aun cuando no contribuyeron a la constitución de un orden burgués "normal"); consecuencias que aún hay que estudiar. ${ }^{60}$ Carece también de fundamento la tesis (actualizada últimamente por autores de ultraizquierda) de que al no consumarse la revolución de independencia, el desarrollo socioeconómico de Latinoamérica, deformado y dependiente en lo político, quedaba fijado irrevocablemente. Esta interpretación fatalista, hace caso omiso de las posibilidades alternativas que desde 1830 se hallaban en embrión en las innúmeras acciones revolucionarias. $^{61}$ Aun cuando el conocimiento de la historia de los movimientos revolucionarios en Latinoamérica a lo largo del siglo $\mathrm{XIX}$, resulta todavia el hijastro de la investigación, los hechos conocidos $^{62}$ refutan claramente todo pesimismo histórico.

Quien quiera dejar al descubierto el papel que desempeñaron los elementos de clase campesino-indigenas, plebeyos y pequeñoburgueses y su cambiante influencia sobre el curso de las fases revolucionarias, se verá ante la necesidad de un análisis de la ya nombrada guerrilla, que constituye igualmente un problema que no ha sido aún "objeto de una investigación profunda". ${ }^{63}$ No hay duda que las acciones guerrilleras apoyadas en una auténtica base de masas, durante la segunda fase de la revolución, se convirtieron en un instrumento político militar muy importante en contra de la potencia colonial española. En vista de la tendencia a juicios generalizadores de acento modernista, ${ }^{64}$ parece adecuado llamar la atención sobre un examen diferenciado en el siguiente sentido: en México la guerrilla revolucionaria social, dirigida por Hidalgo y Morelos, se volvió punto de partida y portadora de una concepción del estado revolucionario, es decir hizo saltar en pedazos tanto el contenido como el aspecto institucional del marco de emancipación trazado por el ala republicana y liberal del partido

(1) Véase Ch. Griffin, "Only the Beginnings of a Basic Transformation Took Place", en History of Latin American Civilization, publicado por L. Hanke, op. cit., 1967, vol. 2, p. 3.

${ }_{61}$ M. Kossok, J. Kübler, M. Zeuske, op. cit.

': C. M. Rama, Die Arbeiterbewegung in Lateinamerika. Chronologie und Bibliographie 1492-1966, Berlin-Zurich, 1967.

${ }^{6}{ }^{3}$ G. Kahle, "Ursprünge und Entwicklung der mexikanischen Guerrilla-tradition", en Jahrbuch für Geschichte, Staat, Wirtschaft und Gesellschaft Lateinamerikas, Colonia-Graz, 1967, t. 4, p. 567.

tot Un resumen demasiado generalizado proporciona G. Kahle, Ursprünge und Probleme lateinamerikanischer Guerrillabewegungen im 19. Jahrhundert, XIII Congreso internacional de historiadores, Moscú, 1970. 
criollo de la revolución. Rasgos análogos surgieron en las acciones dirigidas por Artigas en la Banda Oriental. ${ }^{65}$ Otra función, diferente, mucho más limitada, tuvieron los movimientos de guerrilla de los monteros bolivianos, argentinos o chilenos, que constituyeron un elemento importante de resistencia militar (sobre todo bajo las condiciones de la superioridad ofensiva temporal de los realistas) pero sin fungir como iniciadores de una radicalización social de la revolución. Un ejemplo notable de guerrilla controlada por los patriarcas terratenientes, que al mismo tiempo representaba a ciertas tendencias del separatismo local y regional, fue el movimiento que operaba en el norte de Argentina bajo la dirección de Marín Güemes. ${ }^{66}$ De ninguna manera debe dejarse de lado, finalmente, la guerrilla contrarrevolucionaria cuya amplitud e influencia no debe menospreciarse y que de una manera dramática señaló la posibilidad de ganar para la causa contraria a ciertas capas sociales (sobre todo de las zonas "fronterizas"). ${ }^{67}$

La unidad y la multiplicidad en el proceso de la revolución anticolonial, la convergencia y la divergencia de fuerzas e intereses de clase, lo general y lo particular en el trasfondo de una época revolucionaria de dimensión histórica universal, se presentan en una desconcertante plétora de problemas que junto con su investigación necesitan de la sistematización. Esto, por lo que toca al curso y carácter de la revolución de independencia tanto como por su prehistoria, que mucho se adentra en el pasado colonial. Un ejemplo de esto, sobre el que habría que meditar, es el perfil ideológico de la revolución. A pesar de los esfuerzos realizados por el llamado revisionismo histórico, por poner en tela de juicio la influencia de la Ilustración sobre la preparación intelectual y el pensamiento político-institucional de la revolución, las investigaciones más serias en torno a la historia de la ideología han confirmado aún más esta conexión. ${ }^{68}$

Con la adopción de ideas de la Ilustración y una elaboración propia de ellas, la revolución de independencia latinoamericana, ingresó, también en lo político e intelectual, a la época histórica marcada por la burguesía revolucionaria. ${ }^{69}$ Hasta aquí, el aspecto general, que también (como ya insistimos) debería encontrar atención al proceder a una definición de la revolución de independencia como revolución burguesa no consumada. Son necesarios nuevos intentos de investigación que se contrapongan a una cierta esquematización de los aspectos histórico-ideológicos, como serian:

¿Qué decir respecto de la "fisonomía colonial" de la Ilustra-

${ }^{65}$ N. de la Torre, J. C. Rodríguez, L. Sala de Touron, La revolución agraria artiguista 1815-1816, Montevideo, 1969.

to L. Paso, Los caudillos y la organización nacional, Buenos Aires, 1965, p. 43.

67 Véase G. Carrera Damas, Materiales para el estudio de la cuestión agraria en Venezuela (1808-1830). Caracas, 1964, t. I, p. VII y ss.

"is M. Kossok, "Aufklärung in Lateinamerika: Mythos oder Realitāt?", en $M$. Kossok, H. W. Seiffert, H. Grasshoff, E. Werner, Aspekte der Aufklarungsbewegung, Berlin, 1974, p. 5 y ss.

n" W. Bahner, "Zur Einordnung der "Aufklärung, in die literarhistorische Periodisierung", en E. Engelberg, W. Bahner, W. Dietze, R. Weimann, Genese und Gültigkeit von Epochenbegriffen. Theoretischmethodologische Prinzipien der Periodisierung. Berlín, 1974, p. 25 y ss. 
ción latinoamericana es decir, aquella tajante distancia entre el radicalismo político y una conducta socioeconómica conservadora, distancia que es mayor aquí que en Europa (pero muy comparable a la de los Estados Unidos)?

¿Qué fuentes de la Ilustración (Francia, Italia, España, etc.) ejercieron su influencia de variable intensidad, en qué regiones de Latinoamérica?

¿De qué magnitud fue la influencia real ejercida por las personalidades con frecuencia apostrofadas como "jacobinas"? ¿Representaban un amplio movimiento o apenas un círculo político literario de resonancia limitada?

¿Cómo tuvo lugar la transformación, para las masas, de los principios de la Ilustración? Tomando como ejemplo el movimiento revolucionario mexicano dirigido por Hidalgo y Morelos, se puede concluir que la herejía con tintes religioso-sociales convenció de una manera mucho más radical de lo que hubiese logrado una Ilustración "tipica" deísta o ateísta. ${ }^{70} \mathrm{Ni}$ Voltaire ni Rousseau. sino la virgen de Guadalupe fue el estandarte de la insurrección campesino-indígena.

En correspondencia a la sistematización ideológica varió el papel de la Revolución francesa como revolución modelo para el ciclo del movimiento de Independencia en su totalidad. La tesis "revisionista" de E. de Gandía de que "La revolución francesa no tuvo la menor influencia sobre la independencia del Nuevo Mundo", 71 aparte de su falsedad histórica, ${ }^{72}$ se aparta por completo del meollo del problema. El historiador se ve ante la tarea mucho más complicada de encontrar las pruebas de una actitud diferente con respecto a la Revolución francesa por parte de cada una de las clases y capas, en distintos momentos.

En la adopción de determinados modelos influye menos -y nunca de manera fundamental- la cercanía temporal que la objetiva específica afinidad de clase. (¿Quién podría negar que las generaciones posteriores trataron de "aprender" de las revoluciones anteriores, tanto en sentido positivo como negativo?) ¿Qué significa la negación, tomada como ejemplar, que Francisco de Miranda hace de la Gran Revolución? ${ }^{73}$

La inmadurez del elemento burgués, la ausencia de una influencia jacobina $y$, por consecuencia, la hegemonía de las diversas fracciones de los criollo-aristócratas, contribuyeron a que, para los exponentes de la clase dominante, no fuera la Revolución francesa, sino la norteamericana de 1755 la revolución modelo predominante tanto en lo ideal como en lo real. A todas las fuerzas comprometidas en una lucha contra la radicalización social era más cercana la moderada imagen norteamericana, que armonizaba el progreso liberal con la esclavitud en las plantaciones. A

71 J. Lafaye, Quetzalcóatl et Guadalupe. Eschatologie et Histoire au Mexique (1521-182I). Paris, 1972, t. I., p. 342 y ss.

E. de Gandia, Napoleón y la independencia de América, Buenos Aires, 1955 , p. 11 .

M. Kossok, "Robespierre vu par les artisans de I'Indépendance de l'Amérique espagnole", en Actes du colloque Robespierre, Paris, 1967, p. 157 y ss.

E. de Gandía, op. cit., p. 271 y ss. Véase la interpretación que de este problema hacen J. Grigulievich, Lavretski, Miranda, La vida ilustre del Precursor de la Independencia de América Latina, Caracas, 1974, p. 117 y ss. 
partir de 1793-94, se retiró la euforia por Francia a los "razonables" límites de 1791.

Muy otro fue el movimiento popular radical y sus representantes desde Toussaint L'Ouverture y Gual y España hasta Hidalgo y Morelos y Artigas y Marino; ellos se adhirieron a la "ley de los franceses", presintiendo y reconociendo que la revolución de 1789 "expresaba más las necesidades del mundo de entonces que las realidades", como dijo Marx, que demarcaban el más estrecho campo de acción de las transformaciones de la época. 